\title{
An Autopsy Study of Cranio-Cerebral Injuries Due to Road Traffic Accidents
}

\author{
Gandla Bala Maddileti ${ }^{1}$, A.Dominic Infant Raj ${ }^{2}$, Rajendra Kumar ${ }^{3}$, Gajula Mahesh $^{4}$, Yamini.K \\ ${ }^{1}$ Associate Professor, ${ }^{2}$ Assistant Professor, ${ }^{3}$ Professor and Head, Department of Forensic Medicine, Trichy SRM \\ Medical College Hospital and Research Centre, Irungalur, Trichy, ${ }^{4}$ Associate Professor, Department of Forensic \\ Medicine, Govt Medical College, Anantapuram, ${ }^{5} 1^{\text {st }}$ year PG. Dept of Oral Pathology and Microbiology, Indira \\ Gandhi Institute of Dental Sciences, Puducherry.
}

\begin{abstract}
Cranio-cerebral injuries are a morbid state, resulting from gross structural changes to the scalp, skull and the contents of the cranium. In present scenario, accidents are now considered as one of major contributing factors of Non-Communicable Diseases which have become major health problems of developing countries like India. According to the national crime bureau statistics In India, over 1,46,133 people were killed in various road traffic accidents during 2015 and the count raised to 1,50,785 in 2016. Information on the contributing factors is mandatory to reduce this burden. A prospective study of all Road Traffic accidents coming for autopsy at Government Medical College, Anantapuram. Majority of victims were male in the age group between 31-40 years. Most of them had Linear fractures of the skull along with Sub dural haemorrhage. Two Wheeler riders were the most common victims. Most of the victims died due to CranioCerebral Injury. Most of the times, it is the negligence, which results in an accident. The negligence may be on the part of the victim or may be there on the part of other person who occupied the second vehicle. Sometimes innocent pedestrians are also victimized to these deaths. An accident for all practical purposes is preventable, provided if it is anticipated and proper precaution and preventive measures are adopted.
\end{abstract}

Key words : Road traffic accidents, Intracranial Hemorrhage, Skull fractures, Pedestrian

\section{Introduction}

Road traffic accidents (RTA) can be defined as ", An accident that occurred on a way or street open to public traffic; resulted in one or more persons being killed or injured and at least one moving vehicle was involved. Thus RTA is collisions between vehicles, between vehicles and pedestrians; between vehicles and animals; or between vehicles and geographical or architectural obstacles ${ }^{[1]}$." Road Traffic Accidents (RTA) are increasing in alarming ways. Globally nearly 1.2 million people killed in RTA during the year 2002 . Developing and underdeveloped countries accounted for $80 \%$ of these deaths and $21 \%$ of total injury projected

\footnotetext{
Corresponding Author:

Dr. Dominic Infant Raj

E Mail Id: dodombbs@gmail.com.

Mobile Number: 9597483414, 9949225606
}

estimations reveals that fatalities due to RTA will be the 3rd leading cause of death by 2020 moving from its present 9th position ${ }^{[2]}$.Developing countries are very different from the industrialized countries with regard to the environment and mix of vehicles in the traffic stream ${ }^{[3]}$. Number of 'Traffic Accidents' in the country have been increased by $3.1 \%$ (from $4,81,805$ in 2014 to $4,96,762$ in 2015 ) during 2015 compared to $2014 .{ }^{[4]}$ Road Traffic Accidents (RTAs) are an important public health problem requiring urgent attention in developing countries such as India, which has the highest proportion of deaths due to RTAs in South East Asia. One of the main causes of death and disability is road traffic injuries, with an unequal number of incidences in developing countries. $^{[5]}$. In 2000, RTA were the ninth leading cause of disability-adjusted life years lost and are projected to become third by $2020 .{ }^{[6]}$ Every year, more than 20 million people are injured or disabled and 1.17 million are killed because of RTAs. ${ }^{[6]}$ In developing countries, more than $85 \%$ of the deaths and nearly $90 \%$ of the 
disabilities are caused by RTAs globally. ${ }^{[7]}$ In India, of the mortality of 2,123.60 from all causes, 1,463 are caused by RTA. The World Health Organization (WHO) report on Global Status Report on Road Safety, which is the first of its type, states that, with more than 130,000 deaths annually, India has overtaken China and now has the worst RTA rate worldwide. ${ }^{[8]}$

\section{Materials and Method}

All the post-mortem examinations conducted in Ananthapuram medical college mortuary on deaths due to road traffic accidents during 2016 year were analysed. The data regarding pattern of injuries leading to death, blood alcohol levels in the dead victims, age group affected, statistics of deaths among pedestrians and two wheeler drivers were collected for analysis. The study was conducted with the permission and help of medical records section and autopsy surgeons who have done post-mortem examination in various cases of deaths due to road traffic accidents. All cases of head injuries and injuries over other parts of the body due to RTAs are taken for the study. Decomposed bodies are not included in the present study. A total number of 234 cases were studied during the year 2016. This study included detailed history regarding the incident and complete clinical history including operative procedures, if any and detailed external and internal examination of the body.

\section{Observation and Results}

The current study conducted on 234 deaths due to road traffic accidents for which autopsy done in mortuary of Anantapuram government medical college, Andhra Pradesh during the year of 2016.

Out of 234 deaths majority victims were males. Males accounted to $150(64 \%)$ and females were 84 (36\%). As per age wise observation 73 deaths(males 45 , females 28) occurred in the age group of 31-40 years. In the age group of 41 to 50 years the number of deaths were 58 (males 37, females 22). Next age group is 21 to 30 years in which 40 deaths (males 25, females 15) occurred; in the age group of 51 to 60 years
25 deaths(males 15, females 10) occurred; in the age group of 10 to 20 years 19 deaths (males 16 , females 3 ) occurred; 14 people (males 8 , females 6)more than 61 years are also died. Whereas 4 children (males 4 and no females ) less than 10 years also died. If we take up the graph the peak is rising towards 31 to 40 years age group both in males and females.

During study of distribution of injuries to other body parts, Maximum number of victims had injuries associated with other body parts (159 cases) followed by head injuries( 75 cases).

In our study different types of extra cranial injuries either alone are in combination were found. Among those abrasion was found in (134) followed by contusion (94), laceration(83), fractures(31), crushing injury (8) incised(6), penetrated(4) injuries respectively.

Out of 234 cases studied, 18 were intact without any fracture of the skull. 216 cases had skull fractures. Among them linear/fissure fractures topped the list of skull fractures (112), followed by, Communited fractures (58), Depressed (20), combined (15), sutural separation (9), crush injuries (expressed fractures) (9) and the least being the ring fractures (2) and no gutter fractures seen and these fractures found either individually or in combination with each other

After opening the skull cavity the different kinds of intra cranial haemorrhages were observed in the study group. The type of intracranial haemorrhages found either individually or in combination with each other. Among these, Subdural haemorrhage either singly or in combination with others was found in 103 head injury cases. Next comes subarachnoid haemorrhage and it was found in 93cases, followed by intra cerebral haemorrhage(14), Extra dural haemorrhage(12) intra ventricular haemorrhage(5), Pontine haemorrhage (5) Cerebellar haemorrhage(2).

It was observed in current study the cranio cerebral injury was the leading cause of death in most of the victims that is in173deaths. Followed by haemorrhagic shock in 47 victims then neurogenic shock. 
Table: 1. Age and Sex wise distribution cases of fatal RTAs

\begin{tabular}{|l|l|l|l|l|l|l|l|}
\hline \multirow{2}{*}{ S.No } & \multirow{2}{*}{ Age } & \multicolumn{2}{|l}{ Male } & \multicolumn{2}{l}{ Female } & \multicolumn{2}{l|}{ Total } \\
\cline { 3 - 8 } & & $\begin{array}{l}\text { No of } \\
\text { cases }\end{array}$ & $\%$ & $\begin{array}{l}\text { No of } \\
\text { cases }\end{array}$ & $\%$ & $\begin{array}{l}\text { No of } \\
\text { cases }\end{array}$ & $\%$ \\
\hline 1 & 4 & 1.71 & 0 & 0 & 4 & 1.71 \\
\hline 2 & $11-20$ & 16 & 6.84 & 3 & 1.28 & 19 & 8.12 \\
\hline 3 & $21-30$ & 25 & 10.68 & 15 & 6.41 & 40 & 17.09 \\
\hline 4 & $31-40$ & 45 & 19.23 & 28 & 11.97 & 73 & 31.20 \\
\hline 5 & $41-50$ & 37 & 15.81 & 22 & 9.40 & 59 & 25.21 \\
\hline 6 & $51-60$ & 15 & 6.41 & 10 & 4.27 & 25 & 10.68 \\
\hline 7 & $>60$ & 8 & 3.41 & 6 & 2.56 & 14 & 5.97 \\
\hline & Total & 150 & & 84 & & 234 & 100 \\
\hline
\end{tabular}

Table:2. Head injury association with other body part injury

\begin{tabular}{|l|l|l|l|}
\hline S.no & Item & No Of Cases & Percentage \\
\hline 1 & Head injury with other body parts injuries & 159 & 67.95 \\
\hline 2 & Only head injury & 75 & 32.05 \\
\hline 3 & Total & 234 & 100 \\
\hline
\end{tabular}

Table:3. Types of extra cranial injuries

\begin{tabular}{|l|l|l|l|}
\hline S.no & $\begin{array}{l}\text { Type of injuries Associated with } \\
\text { headinjuries. }\end{array}$ & Total & Percentage(\%) \\
\hline 1 & Abrasion & 134 & 57.26 \\
\hline 2 & Contusion & 94 & 40.17 \\
\hline 3 & Laceration & 83 & 35.47 \\
\hline 4 & Incised injury & 6 & 25.64 \\
\hline 5 & Penetrated injury & 4 & 17.09 \\
\hline 6 & Crushing injury & 8 & 34.19 \\
\hline 7 & Fractures & 31 & 13.25 \\
\hline
\end{tabular}


Table 4: Frequency of different types of fracture

\begin{tabular}{|l|l|l|l|}
\hline S.no & Types of fracture & Total & Percentage(\%) \\
\hline 1 & Linear/ fissure & 112 & 47.87 \\
\hline 2 & Communited & 58 & 24.78 \\
\hline 3 & Depressed & 20 & 08.54 \\
\hline 4 & Gutter & 0 & 0 \\
\hline 5 & Ring & 2 & 0.86 \\
\hline 6 & Sutural separation & 9 & 3.84 \\
\hline 7 & Combined & 15 & 6.42 \\
\hline 8 & No fracture & 18 & 7.69 \\
\hline 9 & Total & 234 & 100 \\
\hline
\end{tabular}

Table:5. Distribution of the Intracranial haemorrhages with respect to site in cases of fatal RTA

\begin{tabular}{|l|l|l|l|}
\hline S.no & Type of Hemorrhage & $\begin{array}{l}\text { Number } \\
\text { of cases }\end{array}$ & $\begin{array}{l}\text { Percentage } \\
\mathbf{( \% )}\end{array}$ \\
\hline 1 & Extra Dural Hemorrhage (EDH) & 12 & 5.13 \\
\hline 2 & Sub Arachnoid hemorrhage(SAH) & 93 & 39.74 \\
\hline 3 & Sub Dural hemorrhage(SDH) & 103 & 44.02 \\
\hline 4 & Pontine hemorrhage & 5 & 2.13 \\
\hline 5 & Intra cerebral hemorrhage(ICH) & 14 & 5.98 \\
\hline 6 & Cerebellar hemorrhage & 2 & 0.85 \\
\hline 7 & Intraventicular Hemorhage(IVH) & 5 & 2.14 \\
\hline
\end{tabular}

Table:6. Different causes of Death in cases of fatal RTA

\begin{tabular}{|l|l|l|l|}
\hline s.no & Cause of death & Number of cases & Percentage(\%) \\
\hline 1 & Cranio cerbral Injury(CCI) & 173 & 73.93 \\
\hline 2 & Neurogenic Shock(NS) & 9 & 38.46 \\
\hline 3 & Hemorrhagic Shock(HS) & 47 & 20.09 \\
\hline 4 & Septic Shock(SS) & 5 & 2.14 \\
\hline 5 & Total & 234 & 100 \\
\hline
\end{tabular}




\section{Discussion}

Head Injuries are more prone in road traffic accidents. These are due to the exchange of force between the body parts which are moving and the stationary hard objects present on and around the road. Or the human body may be stationary and the moving object come and hit the person wherein there is an exchange of force which results in the deformity of the body parts and the result is the injuries spread over the body surface or internal organs of the body.

The results of our study on the cranio cerebral injury due to RTA were analyzed and compared with other studies conducted at various places in India and abroad.

Table: 1 in our present study maximum number of head injury victims were males in the age group of 3140 years. The reason could be that the males of in this age group are prime earners of the family and remain outdoors during most of the day, risk taking behavior, Male dominance is explained by the fact that, males are more exposed to hazards of road. Similar results were observed in the various studies ${ }^{[9,10,11]}$ while study by shamim monga et $\mathrm{a}^{[12]}$ contrasts our finding where the common age group was between 21-30 years.

Table:2 In our study injuries to other body parts also has happened along with head injury, similar finding found in study by Shobhna et al (13). As most of the victims are from two wheeler accidents and pedistrians, victims had involvement of other body parts after hitting was more common.

Table:3 In present study grazed abrasion was most common associated injury either single or in combination with other injuries. Similar findings were observed in study conducted by Oberoi et al ${ }^{[14]}$. However study conducted by Shobhna et al ${ }^{[13]}$ laceration was most common associated injury. Whenever there is a road traffic accident there is blunt force acting on the victim so it causes injuries like abrasion, contusion, lacerations.

Table:4 In regards to fracture of skull bone, we found that linear fracture was most common, similar findings were observed in studies conducted by Wankhede et al [15], Menon et al [16], Shobhna et al [13]. Type of fracture occurring after vehicular accident depends on various factors e.g. speed, safety measures used, ground over which fall occurs. In severe accidents combination of fractures is observed. In another study which was carried out by kuchewar et al ${ }^{[17]}$, almost $79.87 \%$ of victims

were with skull fracture. Fracture of the vault of skull was more common than the base of the skull and most common type of fracture was linear. These results are similar to the results of our study.

Table:5 In current study, most common type of haemorrhage was subdural (either alone or with combination) which is similar to study conducted by Ravikumar et al (18) and Arvind kumar et al ${ }^{(19)}$ while study by Wankhede et a ${ }^{[15]}$ contrasts our finding where Sub Arachnoid Haemorrhage was most common.

Table: 6 in our study the commonest cause of death was Cranio Cerebral Injury, it is consistant with the study conducted by B. Srinu Naik et al. ${ }^{[20]}$

The findings in the present study most of the vulnerable group road users are, two wheeler riders, and pedestrians . Similar findings observed in the study by Gururaj et al. ${ }^{[10]}$. These groups of road users form the major bulk on Indian roads, and hence, their exposure is higher. Unlike occupants in cars and other heavy vehicles, these road users are directly exposed to the traffic environment,

\section{Summary and Conclusion}

The present study can be summarized and concluded as, head injury deaths due to road traffic accidents are occurring in significant number in day to day medicolegal autopsies. Among Highest number of deaths belonged to age group of 31 to 40 years with male preponderance. Majority Of Head injuries are associated with other body parts injuries and abrasion being the commonest. Linear fracture was most common type of skull fracture, and the Sub Dural Haemorrhage was the leading type of intracranial haemorrhage. Cranio cerebral injury being the commonest cause of death and two wheeler riders being the most vulnerable group of affected road users.

\section{Conflict of Intrest: Nil}

\section{Source of Funding: Self funding.}

Ethical Clearance: Ethical clearance from the institutional ethical committee obtained for the study.

\section{References}

1. En.wikipedia.org. (2019). Traffic collision. [online]. Available at: https://en.wikipedia.org/ wiki/Traffic_collision [Accessed 12 Apr. 2019].

2. WHO | India [Internet]. Who.int. 2019 [cited 13 
April 2019]. Available from: https://www.who. int/violence_injury_prevention/road_traffic/ countrywork/ind/en/

3. WHO Euro Report: Seat belts and other devices to reduce injuries from traffic accidents Euro reports and studies, WHO Copenhagen 1981; 40.

4. National Crime records Bureau (NCRB) (Online) Available at: http://ncrb.gov.in (Accessed on 11 Apr 2019)

5. Murray C, Lopez A. Global mortality, disability, and the contribution of risk factors: Global Burden of Disease Study. The Lancet. 1997;349(9063):14361442.

6. Peden MM, Krug E, Mohan D, Hyder A, Norton R, MacKay M, et al. A Five-Year WHO Strategy for Road Traffic Injury Prevention. Geneva: World Health Organization, 2001.

7. Krug E (Ed.). Injury: A Leading Cause of the Global Burden of Disease. Geneva: WHO, 1999. Available at: www.who.int/ violence_injury_ prevention/index.html

8. The Global Status Report on Road Safety 2013. Available at: http://www.who.int/violence_injury_ prevention/road_safety_status/2013/report/en/ . Accessed on (11 Apr 2019)

9. Khan MK, Hanif SA, Husain M, Huda MF, Sabri I. Pattern of non-fatal head injury in adult cases reported at J.N.M.C. Hospital, A.M U, Aligarh. Indian Acad Forensic Med 2011;33:21)

10. Gururaj G. Road traffic deaths, injuries and disabilities in India: Current scenario. Natl Med J India 2008;21:14-20.

11. Kuchewar SV, Meshram RD, Gadge SJ.Demographic study and medico-legal aspect of fatal road traffic accident in Aurangabad. J Life Sci
2012; 4:7-10.

12. Shamim Monga, Sanjay Gupta, Rajesh Paul, Rachna Dhingra Arora, Rupali, Harsimran Kaur. (A study of morbidity and mortality profile of 500 road traffic accident cases in Malwa region of Punjab IAIM, 2015; 2(1): 44-49.)

13. Shobhna et al, autopsy study of fatal head injuries in Banglore. From www.jebmh.com, Nov.2014, vol. 1, issue 10, pg 1330-1339)

14. SS Oberoi et al Pattern and distribution of injuries in fatal two wheeler accidental cases. J Punjab Acad Forensic Med Toxicol 2011; 11(1):31-33.)

15. Wankhede et al Pattern of Fatal Cranio-Cerebral Injuries in Mumbai Region, J Indian Acad Forensic Med. April-June 2014, Vol. 36, No. 2)

16. Menon A, Nagesh K R. Pattern of fatal head injuries due to vehicular accidents in Manipal, Journal of Indian Academy of Forensic Medicine, 2005, 27(1); 19-22,

17. Kuchewar SV, Meshram RD, Gadge SJ. Demographic study and medico-legal aspect of fatal road traffic accident in Aurangabad. J Life Sci 2012; 4:7-10.)

18. Ravikumar et al study of patterns of head injury in fatal road traffic accidents involving riders and pillion riders. JIAFM, Oct Dec 2013, Vol.35, N0.4,

19. Arvind Kumar et al Fatal road traffic accidents and their relationship with head injuries: An epidemiological survey of five years. Indian Journal of Neurotrauma (IJNT). 2008; Vol. 5, No. 2:63-67)

20. B Srinu Naik1, Shiva Rami Reddy2 Study of Patterns of Fatal Cranio-Cerebral Injuries in Deaths Due to Road Traffic Accidents Medico-legal Update, January-June 2018, Vol.18, No. 1 